\title{
Renin-Angiotensin System is Involved in the Mechanism of Increased Serum Asymmetric Dimethylarginine in Essential Hypertension
}

\author{
Akira Ito, MD; Kensuke Egashira, MD*; Takahiro Narishige, MD; \\ Kouhei Muramatsu, MD; Akira Takeshita, MD*
}

\begin{abstract}
Endothelium-dependent/nitric oxide (NO)-mediated vasodilation is impaired in hypertensive individuals. Asymmetric dimethylarginine (ADMA), an endogenous inhibitor of NO synthase, is synthesized by many types of cells including vascular endothelial cells. The serum level of ADMA is elevated in patients with essential hypertension, but the mechanism for this increase is unknown. Therefore, the present study examined whether the renin-angiotensin system (RAS) is involved. Patients with essential hypertension [systolic blood pressure (BP) $>160 \mathrm{mmHg}$ and/or diastolic BP $>95 \mathrm{mmHg}$ ] were randomized to an angiotensin-converting enzyme (ACE) inhibitor treatment group (perindopril, $4 \mathrm{mg} / \mathrm{day}$ for 4 weeks, $\mathrm{n}=7$ ), an angiotensin II type 1 (AT1) receptor antagonist treatment group (losartan, $50 \mathrm{mg} /$ day for 4 weeks, $\mathrm{n}=7$ ) or a 3 -blocker treatment group (bisoprolol, $5 \mathrm{mg} / \mathrm{day}$ for 4 weeks, $n=7$ ). Before and after the treatment, BP, serum concentration of ADMA and plasma concentration of von Willebrand factor (vWF, a biological marker of endothelial injury) were measured. Perindopril, losartan and bisoprolol decreased BP to a similar extent, and either perindopril or losartan, but not bisoprolol, significantly decreased serum ADMA and plasma vWF. These findings suggest that the RAS may contribute to the mechanism of increased serum ADMA as well as to the endothelial injury observed in hypertensive patients. The vasculoprotective actions of ACE inhibitors or AT1 receptor antagonists may be explained at least in part by amelioration of the endothelial injury through a decrease in the serum ADMA concentration. (Jpn Circ J 2001; 65: $775-778$ )
\end{abstract}

Key Words: Angiotensin II; Angiotensin-converting enzyme; Endothelial injury; Nitric oxide synthase; Von Willebrand factor

$\mathbf{E}$ ndothelium-derived nitric oxide (NO) is a potent vasodilator that plays a critical role in regulating vascular resistance and flow! In addition, NO inhibits key processes in atherogenesis, such as monocyte adhesion, platelet aggregation and vascular smooth muscle proliferation, and in disorders associated with atherosclerosis (eg, hypertension, hypercholesterolemia, diabetes mellitus), there is less endothelium-dependent NO-mediated vasodilation? Impairment of the NO synthase system adversely affects vascular reactions and blood flow and, in addition, because NO inhibits key processes in atherogenesis, an NO deficiency state may contribute to the initiation and the progression of atherosclerosis ${ }^{2,3}$ Although the mechanisms of endothelial vasodilator dysfunction are likely to be multifactorial, one contributing abnormality appears to be increased levels of asymmetric dimethylarginine (ADMA) 4,5

ADMA is an endogenous competitive inhibitor of NO synthase $^{6}$ and serum or plasma levels of ADMA are elevated in individuals with hypertension? hypercholesterolemia, diabetes mellitus, 5 peripheral arterial occlusive

(Received April 25, 2001; revised manuscript received June 6, 2001; accepted June 8, 2001)

Department of Cardiovascular Medicine, Yamaguchi Red Cross Hospital, Yamaguchi and *Department of Cardiovascular Medicine, Graduate School of Medicine, Kyushu University, Fukuoka, Japan

Mailing address: Akira Ito, MD, PhD, Department of Cardiovascular Medicine, Yamaguchi Red Cross Hospital, 53-1 Yawatanobaba, Yamaguchi 753-8519, Japan. E-mail: iakira@mbc.sphere.ne.jp disease $^{8}$ or congestive heart failure? Elevation of ADMA is associated with impaired endothelium-dependent NOmediated vasodilation in the brachial artery ${ }^{4}$ and is also significantly correlated with the intima-media thickness of the carotid artery, a non invasive measure of atherosclerosis 5 ADMA is thought to derive from proteins that have been posttranslationally methylated and subsequently hydrolyzed to release ADMA; ${ }^{10}$ a number of cells elaborate ADMA, including vascular endothelial cells!1 ${ }^{1}$ ADMA may be excreted in the urine or metabolized by the enzyme dimethylarginine dimethylaminohydrolase (DDAH) ${ }^{12}$ to L-citrulline and dimethylamine. We have recently reported that lipid-13 or hyperglycemia-induced ${ }^{14}$ dysregulation of DDAH may play an important role in the elevation of ADMA in hypercholesterolemia or diabetes mellitus, respectively. DDAH has sulfhydryl groups in its structure ${ }^{12}$ and it was recently reported that the antioxidant pyrollidine dithiocarbamate (PDTC) inhibited homocysteine-induced ADMA accumulation in conditioned medium of human endothelial cells by reversing the decreased activity of DDAH ${ }^{15}$ However, it is not understood how the serum concentration of ADMA becomes elevated in humans in vivo.

It has been reported that angiotensin-converting enzyme (ACE) inhibitors improve endothelial function in hypertensive patients, ${ }^{16}$ suggesting that the activation of the reninangiotensin system (RAS) may contribute to the endothelial dysfunction in those individuals. Furthermore, angiotensin II (AII) type I (AT1) receptor antagonists may also have this vasculoprotective action ${ }^{17}$ and they are now widely 
used for cardiovascular disorders. However, it is not understood how these drugs modify the RAS to improve vascular function, although recently, they have been shown to reduce free radical concentrations in patients with coronary artery disease ${ }^{18}$

Therefore, we investigated whether the RAS and/or oxidative stress is involved in the mechanisms of ADMA elevation and endothelial injury in hypertensive patients.

\section{Methods}

\section{Patients}

Untreated patients with essential hypertension (systolic blood presure (BP) $>160 \mathrm{mmHg}$ and/or diastolic BP $>95$ $\mathrm{mmHg}$ ), who gave informed consent to be enrolled in the study, which has been approved by the hospital's Ethics Committee, were randomly assigned to the following treatment groups: (1) an ACE inhibitor group (perindopril, 4 $\mathrm{mg} /$ day, $\mathrm{n}=7$ ), (2) an AT1 receptor antagonist group (losartan, $50 \mathrm{mg} /$ day, $\mathrm{n}=7$ ) or (3) a $\beta$-blocker (bisoprolol, 5 $\mathrm{mg} /$ day, $\mathrm{n}=7$ ). All patients had normal renal function. Patients with hypercholesterolemia (serum cholesterol $>240 \mathrm{mg} / \mathrm{dl}$ ), diabetes mellitus (fasting serum glucose $>120$ $\mathrm{mg} / \mathrm{dl}$ ), suspicion of coronary artery disease or peripheral arterial occlusive disease, a history of congestive heart failure or stroke were excluded, because each one of those conditions may increase serum ADMA levels.

\section{Evaluation}

Before and 4 weeks after the treatment, the following measurements were performed.
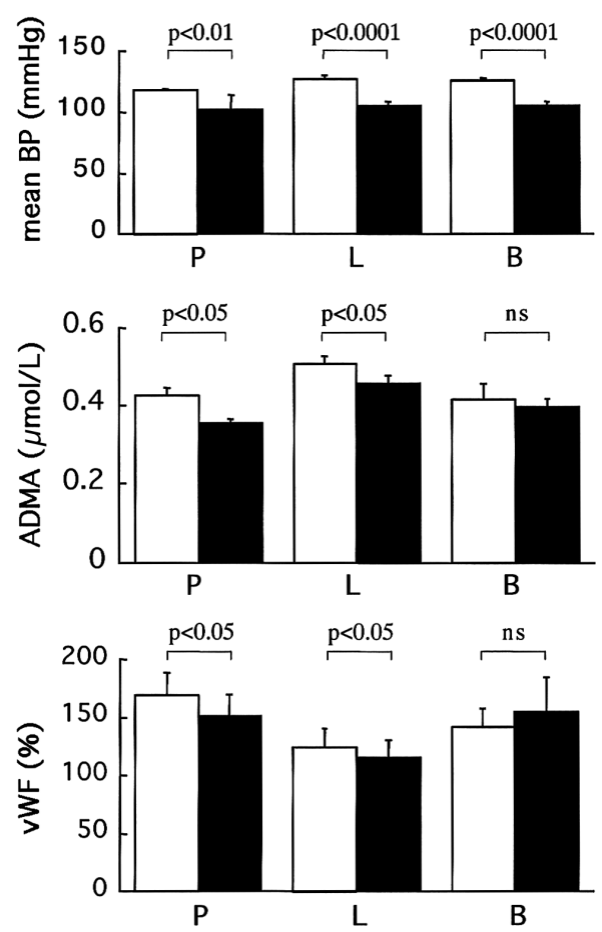

Fig 1. Changes of mean blood pressure (BP) (Top), serum asymmetric dimethylarginine (ADMA) concentration (Middle) and plasma von Willebrand factor (vWF) level (Bottom). P, L and B, treatment with perindopril, losartan and bisoprolol, respectively. In each treatment group, open and closed bars indicate before and 4 weeks after the treatment, respectively.
(1) BP was measured in the seated positions after several deep breaths.

(2) Serum ADMA concentration was measured by highperformance liquid chromatography. The variability of the method was less than $7 \%$, and the detection limit of the assay was $0.15 \mu \mathrm{mol} / \mathrm{L}$.

(3) Plasma concentration of von Willebrand factor (vWF, a marker of endothelial injury) was measured by an enzyme immunoassay technique. It has been reported that an increased level of vWF is associated with impaired endothelium-dependent vasodilation ${ }^{19}$ and that it can predict the appearance or progression of atherosclerosis in patients with hypertension. ${ }^{20}$

(4) Serum ACE activity, plasma AII concentration and serum malondialdehyde-modified low density lipoprotein (MDA-LDL) (a marker of oxidative stress) were also determined.

The within-run coefficient of variation for vWF or MDALDL was $2-3 \%$ or $4-8 \%$, respectively, and the detection limit of the assay for MDA-LDL was $12.5 \mathrm{U} / \mathrm{L}$.

\section{Statistical Analysis}

Values are expressed as mean \pm SE. Differences among treatment groups were tested by ANOVA. Between before and after the treatment, differences were evaluated by paired Students' t test; $\mathrm{p}<0.05$ was considered statistically significant.

\section{Results}

The clinical characteristics of the patients are shown in Table 1. There were no significant differences between the 3 treatment groups in age, sex, BP, heart rate, serum cholesterol, high density lipoprotein cholesterol or fasting glucose levels at baseline. Before the treatment, there were no significant differences in serum ADMA, plasma vWF, serum ACE activity, plasma AII or serum MDA-LDL.

Four weeks after the treatment, mean BP was significantly decreased to the same extent by all 3 treatments (Fig 1), and similarly for systolic and diastolic BP (data not shown). Only perindopril or losartan, but not bisoprolol, significantly decreased both serum ADMA concentrations and plasma vWF levels (Fig 1). Serum ACE activity was significantly suppressed only by perindopril (data not shown), and plasma AII concentration was significantly increased only by losartan (data not shown). Serum MDALDL was significantly decreased only by losartan (from $158 \pm 32$ to $130 \pm 27 \mathrm{U} / \mathrm{ml}, \mathrm{p}<0.05)$.

\section{Discussion}

The salient findings of this study are: (1) serum ADMA concentration was significantly decreased by an ACE inhibitor (perindopril) or an AT1 receptor antagonist (losartan), but not by a $\beta$-blocker (bisoprolol), and (2) plasma vWF, a marker of endothelial injury, was also significantly decreased by either perindopril or losartan, but not by bisoprolol, although these 3 agents decreased BP to the same extent.

This study provides insight into a novel mechanism by which activation of the RAS may disturb both the NO synthase pathway and endothelial function in essential hypertension.

Increased levels of ADMA, the endogenous NO synthase inhibitor, are observed in individuals with hypertension ${ }^{7}$ 
Table 1 Baseline Characteristics of Patients

\begin{tabular}{lccc}
\hline \hline & Perindopril & Losartan & Bisoprolol \\
\hline Age (years) & $58 \pm 3$ & $59 \pm 4$ & $53 \pm 2$ \\
M/F & $3 / 4$ & $4 / 3$ & $3 / 4$ \\
Systolic BP $(\mathrm{mmHg})$ & $165 \pm 2$ & $174 \pm 4$ & $171 \pm 5$ \\
Diastolic BP $(\mathrm{mmHg})$ & $97 \pm 2$ & $103 \pm 3$ & $104 \pm 2$ \\
Mean BP $(\mathrm{mmHg})$ & $118 \pm 2$ & $127 \pm 3$ & $126 \pm 2$ \\
Heart rate $($ beats/min) & $65 \pm 3$ & $69 \pm 4$ & $76 \pm 7$ \\
Total cholesterol $(\mathrm{mg} / \mathrm{dl})$ & $211 \pm 16$ & $201 \pm 15$ & $225 \pm 22$ \\
HDL cholesterol $(\mathrm{mg} / \mathrm{dl})$ & $58 \pm 6$ & $60 \pm 4$ & $58 \pm 6$ \\
Triglyceride $(\mathrm{mg} / \mathrm{dl})$ & $73 \pm 11$ & $92 \pm 13$ & $119 \pm 17$ \\
Glucose $(\mathrm{mg} / \mathrm{dl})$ & $100 \pm 3$ & $99 \pm 5$ & $110 \pm 3$ \\
Serum ADMA $(\mu \mathrm{mol} / \mathrm{L})$ & $0.43 \pm 0.02$ & $0.51 \pm 0.02$ & $0.42 \pm 0.04$ \\
Plasma $\mathrm{vWF}(\%)$ & $170 \pm 20$ & $125 \pm 16$ & $143 \pm 16$ \\
Serum ACE activity $\left(\mathrm{IU} / \mathrm{L}\right.$ at $\left.37^{\circ} \mathrm{C}\right)$ & $10.9 \pm 1.2$ & $12.7 \pm 1.8$ & $9.3 \pm 2.3$ \\
Plasma AII $(\mathrm{ng} / \mathrm{ml})$ & $23 \pm 13$ & $12 \pm 2$ & $17 \pm 3$ \\
Serum $M D A-L D L(\mathrm{U} / \mathrm{L})$ & $115 \pm 32$ & $158 \pm 32$ & $118 \pm 22$ \\
\hline
\end{tabular}

$B P$, blood pressure; ADMA, asymmetric dimethylarginine; $v W F$, von Willebrand factor; ACE, angiotensin-converting enzyme; AII, angiotensin II; MDA, malondialdehyde-modified.

and may account in part for the endothelial vasodilator dysfunction observed in this condition. Increased ADMA levels are associated with reduced $\mathrm{NO}$ elaboration in both hypercholesterolemic ${ }^{4}$ and atherosclerotic patients ${ }^{8}$ as judged by reduced nitrate excretion and impaired endothelium-dependent, NO-mediated forearm vasodilation.

It has been reported that in healthy humans the serum ADMA level is around $0.5 \mu \mathrm{mol} / \mathrm{L}$. In the present study, the serum ADMA level was not elevated, which may be because the severity or the duration of hypertension also contributes to the elevation of serum ADMA. Further studies are needed to examine the effects of ACE inhibitors or AT1 receptor antagonists on ADMA levels in patients with severe hypertension or with other risk factors for atherosclerosis.

We measured plasma vWF as a marker of endothelial injury, but $\mathrm{vWF}$ is thought to be increased in disorders with endothelial dysfunction? ${ }^{1}$ Therefore, one of the limitations of this study is that endothelial function itself was not evaluated, for example, by measurement of flow-dependent vasodilation of brachial artery using an ultrasound technique 22

Although the difference between the 3 treatment groups in serum ADMA concentration or plasma vWF level before the treatments was not statistically significant (Table 1), there was some degree of difference among them. Furthermore, there was no correlation between ADMA and vWF, and the decrease of ADMA by perindopril or losartan was only about $10 \%$. These results suggest that some factors other than those measured in this study, such as serum homocystein levels etc, might be related to endothelial function, and that the elevation of ADMA is just one of the key factors contributing to endothelial dysfunction.

We recently demonstrated that lipid-13 ${ }^{13}$ or hyperglycemiainduced ${ }^{14}$ dysregulation of DDAH, a degradation enzyme of ADMA, plays an important role in the elevation of ADMA in hypercholesterolemia or diabetes mellitus, respectively. Oxidative stress has been suggested as one of the mechanisms of its decreased activity 15 In the present study, we measured serum MDA-LDL as a marker of oxidative stress. Losartan, but not perindopril or bisoprolol, significantly decreased serum MDA-LDL, suggesting that losartan might decrease serum ADMA by reducting oxidative stress, and that other mechanisms are involved in the perindopril-induced decrease of serum ADMA. Further studies are needed to clarify the role of DDAH in the effects of ACE inhibitors or AT1 receptor antagonists on serum ADMA levels in hypertensive patients.

ADMA is widely distributed in tissues ${ }^{12}$ and may be the mechanism for controlling NO synthesis in physiological and/or pathological states. We have demonstrated that the RAS may be involved in the elevation of serum ADMA in essential hypertension and our results suggest that the vasculoprotective actions of ACE inhibitors or AT1 receptor antagonists can be explained at least in part by the amelioration of endothelial injury (dysfunction) through the decreased serum ADMA concentration.

\section{References}

1. Furchgot RF, Zawadzki JV: The obligatory role of endothelial cells in the relaxation of arterial smooth muscle by acetylcholine. Nature 1980; 288: $373-376$

2. Cooke JP, Dzau VJ: Derangements of the nitric oxide synthase pathway, L-arginine, and cardiovascular diseases. Circulation 1997; 96: $379-382$

3. Takemoto M, Egashira K, Usui M, Numaguchi K, Tomita H, Tsutsui $\mathrm{H}$, et al: Important role of tissue angiotensin-converting enzyme activity in the pathogenesis of coronary vascular and myocardial structural changes induced by long-term blockade of nitric oxide synthesis in rats. J Clin Invest 1997; 99: 278-287

4. Boeger RH, Bode-Boeger SM, Szuba A, Tsao PS, Chan JR, Tangphao $\mathrm{O}$, et al: Asymmetric dimethylarginine (ADMA): A novel risk factor for endothelial dysfunction: Its role in hypercholesterolemia. Circulation 1998; 98: 1842-1847

5. Miyazaki H, Matsuoka H, Cooke JP, Usui M, Ueda S, Okuda S, et al: Endogenous nitric oxide synthase inhibitor: A novel marker of atherosclerosis. Circulation 1999; 99: 1141-1146

6. Vallance P, Leone AM, Calver A, Collier J, Moncada S: Endogenous dimethylarginine as an inhibitor of nitric oxide synthase. J Cardiovasc Pharmacol 1992; 20(Suppl 12): 560-562

7. Surdacki A, Nowicki M, Sandmann J, Tsikas D, Boeger RH, BodeBoeger SM, et al: Reduced urinary excretion of nitric oxide metabolites and increased plasma levels of asymmetric dimethylarginine in men with essential hypertension. J Cardiovasc Pharmacol 1999; 33: $652-658$

8. Boeger RH, Bode-Boeger SM, Thiele W, Junker W, Alexander K, Froelich JC, et al: Biochemical evidence for impaired nitric oxide synthesis in patients with peripheral arterial occlusive disease. Circulation 1997; 95: 2068-2074

9. Usui M, Matsuoka H, Miyazaki H, Ueda S, Okuda S, Imaizumi T: Increased endogenous nitric oxide synthase inhibitor in patients with congestive heart failure. Life Sci 1998; 62: 2425-2430

10. Kakimoto $\mathrm{Y}$, Akazawa S: Isolation and identification of $\mathrm{N}^{\mathrm{G}}, \mathrm{N}^{\mathrm{G}}$ - and $\mathrm{NG}^{\mathrm{G}}, \mathrm{N}^{\prime} \mathrm{G}$-dimethylarginine, $\mathrm{N}$-mono. Di-, and trimethyllysine, and glucosylgalactosyl- and galactosyl $\delta$-hydroxylysine from human urine. J Biol Chem 1970; 245: 5751-5758 
11. Fickling S, Leone AM, Nussey SS, Vallance P, Whitley GStJ: Synthesis of $\mathrm{N}^{\mathrm{G}}, \mathrm{N}^{\mathrm{G}}$ dimethylarginine by human endothelial cells. Endothelium 1993; 1: 137-140

12. Kimoto M, Whitley GS, Tsuji $\mathrm{H}$, Ogawa $\mathrm{T}$ : Detection of $\mathrm{N}^{\mathrm{G}}, \mathrm{NG}_{-}$ dimethylarginine dimethylaminohydrolase in human tissues using a monoclonal antibody. J Biochem 1995; 117: 237-238

13. Ito A, Adimoolam S, Tsao PS, Kimoto M, Ogawa T, Cooke JP: Novel mechanism for endothelial dysfunction: Dysregulation of dimethylarginine dimethylaminohydrolase. Circulation 1999; 99: 3092-3095

14. Ito A, Asagami T, Tsao P, Adimoolam S, Kimoto M, Tsuji H, et al: Dysregulation of dimethylarginine dimethylaminohydrolase: A mechanism of endothelial dysfunction in diabetes mellitus. Circulation 1999; 100(Suppl I): I-473

15. Stuehlinger MC, Tsao PS, Kimoto M, Cooke JP: Homocysteine induced accumulation of asymmetric dimethylarginine: Role of DDAH and effect of antioxidants. Circulation 2000; 102(Suppl): II177

16. Rizzoni D, Muiesan ML, Porteri E, Castellano M, Zulli R, Bettoni G, et al: Effects of long-term therapy with lisinopril on resistance arteries of hypertensive patients with left ventricular hypertrophy. $J$ Hypertens 1997; 15: 197-204
17. Schiffrin EL, Park JB, Inteagar HD, Touyz RM: Correction of arterial structure and endothelial dysfunction in human essential hypertension by the angiotensin receptor antagonist losartan. Circulation 2000; 101: $1653-1659$

18. Berry C, Anderson N, Hamilton LA, Pathi V, Kirk AJB, McMurray $\mathrm{JJ}$, et al: Renin-angiotensin system inhibition reduces free radical concentrations in arteries of patients with coronary heart disease. Circulation 2000; 102(Suppl): II-123

19. Blann AD: von Willebrand factor and the endothelium in vascular disease. Br J Biomed Sci 1993; 50: 125-134

20. Blann AD, Waite MA: von Willebrand factor and soluble E-selectin in hypertension: Influence of treatment and value in predicting the progression of atherosclerosis. Coronary Artery Dis 1996; 7: 143 147

21. Lip GYH, Blann A: von Willebrand factor: A marker of endothelial dysfunction in vascular disorders? Cardiovasc Res 1997; 34: 255265

22. Celermajer DS, Sorensen KE, Gooh VM, Spiegelhalter DJ, Miller OI, Sullivan ID, et al: Non-invasive detection of endothelial dysfunction in children and adults at risk of atherosclerosis. Lancet 1992; 340: $1111-1115$ 